\title{
The Relational Wear and Tear of Everyday Racism Among African American Couples
}

\author{
Anthony D. Ong ${ }^{1,2^{*}}$, Betul Urganci ${ }^{1}$, Anthony L. Burrow ${ }^{1,3}$, and Tracy DeHart ${ }^{4}$ \\ ${ }^{1}$ Department of Psychology, Cornell University \\ ${ }^{2}$ Center for Integrative Developmental Science, Cornell University \\ ${ }^{3}$ Bronfenbrenner Center for Translational Research, Cornell University \\ ${ }^{4}$ Department of Psychology, Loyola University Chicago
}

\begin{abstract}
Author Note
Anthony Ong (iD https://orcid.org/0000-0002-5032-667X

Betul Urganci iD https://orcid.org/0000-0001-7449-7804

Anthony Burrow (iD https://orcid.org/0000-0003-1247-0985

The authors declare no conflict of interest with respect to the authorship or publication of

Correspondence concerning this article should be addressed to Anthony Ong, Department of Psychology, Cornell University, Ithaca, NY 14853-4401.

Contact: anthony.ong@ cornell.edu
\end{abstract} this article. 


\begin{abstract}
The wear and tear of adapting to chronic stressors such as racism and discrimination can have detrimental effects on mental and physical health. Here, we investigate the wider implications of everyday racism for relationship quality in a sample of 98 heterosexual African American couples. Participants reported on their experiences of racial discrimination and positive and negative affect for 21 consecutive evenings. Using dyadic analyses, we show that independent of age, gender, marital status, income, racial discrimination frequency, neuroticism, and mean levels of affect, participants' relationship quality was inversely associated with their partner's negative affective reactivity to racial discrimination. Associations did not vary by gender, suggesting that the effects of affective reactivity were similar for men and women. These findings highlight the importance of a dyadic approach and call for further research examining the role of everyday racism as a key source of stress in the lives of African American couples.
\end{abstract}

Keywords: African American, affective reactivity, discrimination, racism, relationship quality 


\section{Statement of Relevance}

Psychological science has long studied the nature of racism and its consequences for individual cognition and health. In this research, we asked whether experiences of everyday racism impact the relational well-being of African American couples. This question is especially pressing given that psychological science can inform research and practice and ultimately public discourse on how best to combat the detritus of everyday racism. Using dyadic data, we found that individuals' perceptions of relationship quality are predicted by their partners' affective reactivity to day-to-day racial discrimination. These findings advance our understanding of the social effects of everyday racism and the various ways it can impinge on the interpersonal flourishing of African American couples. 


\section{The Relational Wear and Tear of Everyday Racism among African American Couples}

There is growing evidence that everyday experiences of discrimination in general, and racial discrimination in particular, are associated with negative relationships outcomes, including decreased relationship satisfaction (Bryant et al., 2010; Lincoln \& Chae, 2010; Trail et al., 2012) and increased relationship instability and strain (Lavner et al., 2018; Murry et al., 2001; Priest et al., 2020). An important finding emerging from dyadic studies is that in addition to one's own experiences of discrimination (e.g., Doyle \& Molix, 2014; Kerr et al., 2018), partner experiences of discrimination may also influence relationship well-being (e.g., Trail et al., 2012; Wofford et al., 2019). But despite the recognition that racial discrimination is a salient chronic stressor for racial and ethnic minority couples (Bryant et al., 2010; St. Jean \& Feagin, 1998), the day-to-day unfolding of discrimination within couples has rarely been studied, hindering our understanding of racism as a dynamic, interpersonal phenomenon (Harrell, 2000; Smith et al., 2020). Here, we examined whether individual differences in affective responses to racial discrimination in daily life were associated with relationship functioning in African American couples.

\section{Racial Discrimination as a Stressor for African American Couples}

Relative to White Americans, African Americans consistently report more experiences of unfair treatment and discrimination at every level of age, gender, and socio-economic status (Barnes et al., 2004; Forman et al., 1997; Kessler et al., 1999; Lewis et al., 2012). Moreover, studies have documented consistent associations between reports of discrimination and a variety of mental and physical health indicators among African Americans (Clark et al., 1999; Mays et al., 2007; Pieterse et al., 2012). These associations are evident in cross-sectional as well as longitudinal studies (Cuevas et al., 2020; Goosby et al., 2018; Lewis et al., 2015; Paradies et al., 2015; Williams et al., 2019). By contrast, research focusing on the effects of racial 
discrimination on African American interpersonal functioning has only recently begun to receive systematic attention (Clark et al., 2002; Lavner et al., 2018; Smith et al., 2020). Understanding these effects is important due to the interdependence of individuals in close relationships in general (Aron et al., 1991; Arriaga, 2013; Rusbult \& Van Lange, 1996) and the shared experience of racial discrimination among African American couples in particular (Bryant et al., 2010; St. Jean \& Feagin, 1998).

Studies of stress and couple functioning suggest that stressful life events may influence one’s own (e.g., Bolger et al., 1989) and one's partner's relationship quality (e.g., Thompson \& Bolger, 1999). Importantly, by differentiating between actor (or intrapersonal) effects and partner (or interpersonal) effects, dyadic studies of couples have elucidated how stressors can both spread across multiple spheres of life and reverberate beyond one partner to influence the health of the other (Bolger et al., 1990; Neff \& Karney, 2007). To date, most research examining racial discrimination and health among African Americans has focused on actor effects (see Mays et al., 2007, for a review). Yet the study of stress transmission and proliferation requires attention to not only intrapersonal effects (e.g., Ong et al., 2009) but also interpersonal effects (e.g., Barton et al., 2018; Lavner et al., 2018) of racial discrimination.

\section{Affective Reactivity to Daily Stressors}

Increasingly, researchers have turned to daily process designs to probe the dynamic processes that give rise to individual differences in affective reactivity to daily stressors (Charles et al., 2013; Cohen et al., 2005). Operationally, these individual differences are represented by the within-person coupling of daily stress and affect (Bolger \& Zuckerman, 1995). These intraindividual parameter estimates measure a continuum of affective reactivity, such that stronger reactions to daily stressors (e.g., greater increases in negative affect) constitute greater 
vulnerability. Importantly, empirical work demonstrates that heightened affective reactivity is a unique vulnerability factor for subsequent affective disorders (Charles et al., 2013), chronic health conditions (Piazza et al., 2013), inflammation (Sin et al., 2015), allostatic load (Piazza et al., 2019), and mortality (Chiang et al., 2018).

Given the documented breadth of correlates of affective reactivity (see Ong \& Leger, 2021), it is plausible that affective reactivity would be associated with relationships outcomes as well. Leading theoretical models of relationship quality posit that enduring personal vulnerabilities to stressful events (e.g., affective reactivity) account for variations in relationship outcomes over time (Karney \& Bradbury, 1995; Slatcher \& Selcuk, 2017). In longitudinal analyses of married adults from the Midlife in the United States (MIDUS) study, Ong and colleagues (2020) found that greater negative affective reactivity to daily stressors predicted lower marital satisfaction and higher marital risk 10 years later.

Recent research has also provided initial evidence for the role of daily racial discrimination as a specific context for assessing naturalistic emotional processes. For example, building on prior work linking greater reactivity to generic daily stressors with subsequent depressive symptomatology (Charles et al., 2013; Parrish et al., 2011), Ong and Burrow (2018) examined affective reactivity in the context of daily racial discrimination among African Americans. They found that heightened affective reactivity to daily racial discrimination forecasted elevated depressive symptoms 1 year later.

Although the above studies demonstrate the value of within-person, process-oriented methods, a number of central but yet unresolved issues remain. Foremost, while there is interest in the role of enduring vulnerabilities that individuals bring to close relationships (Karney \& Bradbury, 1995), it is unknown whether heightened affective responses to daily discrimination 
impinges on relationship quality in African American couples. Second, the extent to which affective reactivity operates uniquely within couples remains unclear. Theoretical models of racism-related stress posit that affective responses (e.g., anger, humiliation) to everyday discrimination are manifested through both direct and vicarious experiences (Harrell, 2000; Williams et al., 2003).

Third, research on affective reactivity to daily stressors has primarily focused on negative affective states. Maintenance of positive affect may be critical for stemming the damaging effects of daily stressor exposure. For instance, greater reductions in positive affect in response to daily stress have been linked with future depressive symptoms (O’Neill et al., 2004; Ong \& Burrow, 2018), higher levels of inflammatory markers (Sin et al., 2015), lower sleep quality and efficiency (Ong et al., 2013), and even greater mortality risk (Chiang et al., 2018; Mroczek et al., 2012). Fourth, the extent of gender differences in affective reactivity to racial discrimination is important to assess, especially among African American couples in whom perceptions of discrimination and relationship instability are tied to gender discrepant experiences (Lavner et al., 2018; McNeil et al., 2014). Some evidence suggests that African American women may be disproportionately vulnerable to the effects of racial discrimination due to the overall burden of caregiving for others in their social network (Kessler \& McLeod, 1984; Merritt et al., 2011). However, a dyadic study of African American couples by McNeil and colleagues (2013) found no evidence of partner effects of discrimination, suggesting that discrimination experienced by African American men and women did not influence their partner's well-being.

Finally, this present investigation considers the role of negative emotionality traits as potential confounds (for a discussion, see Lilienfeld, 2017; Ong, 2021) in the association between affective reactivity to racial discrimination and relationship quality. Considerable 
evidence indicates that individual differences in neuroticism (a well-established marker of negative emotionality and stress reactivity) may account for differential exposure and reactivity to daily stressors (Bolger \& Schilling, 1991; Bolger \& Zuckerman, 1995; Gunthert et al., 1999). Thus, we controlled for neuroticism in analyses of the associations between affective reactivity and relationship quality.

\section{The Current Study}

The current study addresses these issues by examining associations between daily affective reactivity and relationship quality in a sample of African American couples. Using dyadic data analyses, we examined actor and partner effects of affective reactivity on relationship quality. We tested the primary hypotheses that greater negative affective reactivity to daily racial discrimination is associated with lower relationship quality. Because close relationships are inherently dyadic, we also predicted partner effects, such that greater negative affective reactivity in one partner is expected to impair the relationship perceptions of the other partner. Finally, we explored whether the effects of affective reactivity on relationship quality vary by affective valence and participant gender.

\section{Method}

\section{Participants}

As part of a larger study investigating racial discrimination, relationship processes, and psychological well-being, 180 African American couples were recruited from the broader Chicago, IL area using posters, community message boards, and advertisements on the Chicago Transit Authority (CTA). Couples were eligible if both partners were at least 18 years old, identified as African American, were married or living together, and had internet access. Of the 180 couples who responded, five couples were excluded because at least one member of the dyad 
did not complete any daily diaries. Of the remaining 176 couples, 60 couples were excluded because the computation of affective reactivity requires having both discrimination and nondiscrimination days, and one or both couple members reported experiencing discrimination either every day or none of the days. Of the remaining, data from 17 dyads were excluded from analysis because the partners could not be distinguished by gender and because a large sample of same-gender couples is required to account for dependency between partners when retaining both distinguishable and indistinguishable dyads (Olsen \& Kenny, 2006). The final analytic sample $(N=98$ couples $)$ had a mean age of 35.9 years $(S D=12.3)$. On average, participants had been in their current relationships for 7.1 years $(S D=8.1)$, and $34.5 \%$ were married. The median individual income $(\$ 25,000$ to $\$ 50,000)$ is comparable to that reported in national surveys of African Americans (Chatters et al., 2008), and 98\% completed at least a high school education.

\section{Procedure}

Couples attended an orientation session where they completed a questionnaire assessing relationship quality along with other measures related to a larger study. After the questionnaire assessment, couples received both verbal and written instructions about the diary procedure, which started on the upcoming Monday. Every evening for 21 consecutive days, participants received an e-mail containing a link to an online survey about their daily experiences (e.g., discrimination, positive and negative affect). Participants received an $e$-mail message each day reminding them to access the diary measures. To minimize variation in reporting times, participants could only log on to the Web site between the hours of 8:00 p.m. and 4:00 a.m. The median number of days a participant contributed data was $19(M=17.0$ days, $S D=5.5)$. At the conclusion of the 21-day period, couples were compensated up to $\$ 175$ for their time: $\$ 50$ for the baseline questionnaire and up to $\$ 125$ for the daily diaries. In addition, for every day both 
members submitted a daily survey, couples were entered into a lottery for a chance to win a $\$ 500$ bonus at the end of the study.

\section{Measures}

Relationship Quality. Relationship quality was assessed for each member of the dyad using the Perceived Relationship Quality Components Scale (PRQC; Fletcher et al., 2000). The 18-item scale assesses six components of romantic relationship quality: satisfaction (e.g., "How satisfied are you with your relationship?" "How content are you with your relationship?"), commitment (e.g., "How committed are you to your relationship?" "How dedicated are you to your relationship?"), intimacy (e.g., "How intimate is your relationships?" "How close is your relationship?"), trust (e.g., "How much do you trust your partner?" "How much can you count on your partner?"), passion (e.g., "How passionate is your relationship? "How sexually intense is your relationship?"), and love (e.g., "How much do you love your partner?" "How much do you cherish your partner?”). Each component is assessed by three items. Fletcher et al. (2000) have confirmed that these components are correlated and tap a higher order relationship factor.

Responses were made on a 9-point Likert-type scale (1= Not at all to 9= Extremely). Responses to all 18 items were averaged to form a global index of relationship quality, with higher scores indicating greater perceived relationship quality $(\alpha=.93)$.

Daily racial discrimination. Daily racial discrimination was assessed with a modified version of the Daily Life Experience (DLE) subscale of the Racism and Life Experience scale (Harrell, 1997). The self-report measure assesses the frequency and impact of experiencing 20 different types of racial discrimination (see Utsey, 1998 for a review of scale properties). A recent psychometric study of the DLE subscale demonstrated evidence of reliability, convergent and criterion-related validity, and measurement invariance by gender for African American 
males and females (Lee et al., 2020). The instructions for the checklist were modified to refer to whether each of the 20 events had occurred that day (e.g., "Today, I was ignored, overlooked, or not given service"; “Today, I was mistaken for someone else of my same race.”). A respondent was given a score of 1 if they had experienced a racial discrimination event on a particular day and a score of 0 if they had not. This approach to measuring daily racial discrimination is consistent with research that distinguishes daily events from ongoing activities by defining them as changes from day-to-day occurrences (for a discussion, see Eckenrode \& Bolger, 1997).

Affective reactivity to racial discrimination. Daily positive affect (PA) and negative affect (NA) were measured using the Positive and Negative Affect Schedule (Watson et al., 1988). For NA, participants rated how "angry," "ashamed," "dejected," "distressed," "nervous," and "sad" they felt. For PA, participants rated how "alert," "cheerful," "excited," "happy," “interested," and "proud" they felt. Participants responded using a 9-point Likert-type scale, ranging from 1 (not at all) to 9 (extremely). Within-person estimates of reliability were computed using three-level models in which items were nested within days, which were nested within participants (Bryk \& Raudenbush, 1992, pp. 191-196). Using this procedure, the estimated daylevel reliability was .82 for the PA scale and .85 for the NA scale, respectively.

Following procedures established in other daily stress research (Charles et al., 2013; O’Neill et al., 2004; Piazza et al., 2013), affective reactivity was operationalized as the difference in affect levels between racial discrimination days and non-racial discrimination days. Multilevel modeling was used to estimate reactivity coefficients for each individual using the following equation:

Level 1: Affect $_{i j}=a_{0 j}+a_{1 j}(\text { Discrimination })_{i j}+a_{2 j}(\text { Gender })_{i j}+a_{3 j}(\text { Male })_{i j}+a_{4 j}(\text { Female })_{i j}+r_{i j}$ Level 2: $a_{0 j}=\beta_{00}+u_{0 j}$ 


$$
a_{1 j}=\beta_{10}+u_{1 j}
$$

At Level 1 , the value $a_{0 j}$ is a regression intercept and reflects the mean level of daily affect on days in which the predictor, the dichotomous racial discrimination variable, is zero; $a_{1 j}$ is a regression slope (reactivity coefficient) representing the difference in affect between days when a racial discrimination event was and was not endorsed. Gender was effect-coded $(-1=$ male, $1=$ female $)$. Dummy-coded male $(0=$ female, $1=$ male $)$ and female $(0=$ male, $1=$ female $)$ separated the random intercept into two components for each gender. In this model, the residual parameter $\left(r_{i j}\right)$ indexes the day-to-day variability in affect for each individual. At Level $2, \beta_{00}$ and $\beta_{10}$ represent the sample average level of affect and reactivity effect, respectively. Additionally, $u_{0 j}$ and $u_{1 j}$ are variances reflecting individual differences or deviations from the sample average level of affect and reactivity estimates, respectively. Each person therefore has unique regression parameters, representing their own relationship between racial discrimination and affect. For some people, reactivity coefficients will be larger and for others smaller, or even near zero. As an example, a person with a NA reactivity coefficient of 0.19 (the sample mean) had an increase of 0.19 (on a 1-5 scale) in NA on racial discrimination days compared with non-racial discrimination days. Models were estimated by means of restricted maximum likelihood. Under this estimation procedure, estimates for missing data at Level 1 are obtained via the expectationmaximization algorithm (Raudenbush \& Bryk, 2002).

Covariates. Demographic data on age, gender, marital status, and relationship length were included as covariates. Following prior work (Ong \& Burrow, 2018; Sin et al., 2015), we controlled for average or mean-level affect on non-racial discrimination days to distinguish between the effects of affective reactivity to daily racial discrimination and typical experiences of affect. The number of days during which at least one racial discrimination experience 
occurred was included in all analyses to adjust for individual differences in racial discrimination frequency. Finally, because neuroticism has been shown to be an important correlate of daily stressor exposure and reactivity (Bolger \& Zuckerman, 1995), we controlled for it using the neuroticism subscale of the International Personality Inventory Pool (IPIP; Goldberg, 1992). Responses to the 10 -item measure are based on a 7 -point scale $(1=$ very inaccurate and $7=$ very accurate). Sample items include, "Get stressed out easily" and "Am easily disturbed.” $(\alpha=.85)$.

\section{Analytic approach}

Primary analyses consisted of estimating a series of actor-partner interdependence models (APIM) to evaluate whether affective reactivity to daily racial discrimination was associated with relationship quality. To account for interdependence of individuals within the same dyad, we used dyadic data analysis (Kashy \& Kenny, 2000). Using this method, we can estimate both actor effects (associations between an individual's affective reactivity to racial discrimination and his or her own relationship quality) and partner effects (associations between an individual's affective reactivity to racial discrimination and his or her partner's relationship quality). Both actor and partner effects of NA reactivity and PA reactivity were examined as predictors of relationship quality. Before analysis, data for NA reactivity were winsorized at the $90^{\text {th }}$ percentile to correct for skewness. Additionally, to aid in interpretability, we multiplied the PA reactivity slopes by -1 to reflect lower levels of relationship quality as a function of racism-related decreases in PA.

All analyses were conducted using the DyadR package in R (Garcia \& Kenny, 2020). Unadjusted analyses for NA reactivity were examined in Model 1. Main effects of daily NA on non-racial discrimination days and racial discrimination frequency were added in Model 2. Demographic covariates (i.e., age, gender, income, marital status, relationship length) and neuroticism were added in Model 3. To probe for gender differences, two-way interactions of 
actor and partner NA reactivity with gender were included in Model 4. Parallel models were tested for PA reactivity (Models 5-8). Finally, to evaluate whether PA and NA reactivity were independently associated with relationship quality, both actor and partner effects of both NA and PA reactivity, along with their two-way interactions with gender, were included in Model 9.

\section{Results}

\section{Descriptive Statistics}

Table 1 includes descriptive information and correlations for the study variables. Means, standard deviations, and zero-order correlations are presented for men (lower diagonal) and women (upper diagonal) separately. Actor and partner NA and PA reactivity scores were correlated within couples, such that if one person experienced heightened reactivity, their partner was also likely to have experienced heightened reactivity. Relationship quality was negatively correlated with most actor and partner effects of NA and PA reactivity ( $r$ s range from $|0.20|$ to $|0.30|$ ), except for partner PA reactivity which was not significantly correlated with relationship quality for females $(p=.27)$.

\section{Actor-Partner NA Reactivity and Relationship Quality}

Results from APIM regression models are presented in Table 2. In unadjusted analyses, there was a significant main effect of actor NA reactivity in predicting relationship quality (Model 1; $b=-0.20, p=0.025,95 \%$ CI $[-0.38,-0.03)$. However, this association became nonsignificant when adjusting for mean daily affect, racial discrimination frequency, demographic covariates, and neuroticism (Model 2-4; all ps >0.43). Partner NA reactivity was a significant predictor of relationship quality in univariate analyses (Model $1 ; b=-0.19, p=0.028$, $95 \%$ CI $[-0.37,-0.02])$ and remained significant in models controlling for mean daily affect and racial discrimination frequency (Model 2; $b=-0.19, p=0.034,95 \%$ CI $[-0.37,-0.02])$ and 
demographic factors and neuroticism (Model 3; $b=-0.21, p=0.032,95 \%$ CI $[-0.40,-0.09]$ ).

There was no evidence for any two-way interactions of actor and partner NA reactivity with gender (Model 4; all ps > 0.542).

\section{Actor-Partner PA Reactivity and Relationship Quality}

Parallel APIM analyses were conducted to explore whether actor and partner PA reactivity to racial discrimination predicted relationship quality. As shown in Table 2, actor PA reactivity was significantly associated with relationship quality in unadjusted analyses (Model 5; $b=-0.15, p=0.001,95 \%$ CI $[-0.24,-0.06]))$ and when controlling for mean daily affect and racial discrimination frequency (Model 6; $b=-0.47, p=0.029,95 \%$ CI $[-0.90,-0.05]$ ). However, this association became nonsignificant when adjusting for demographic covariates and neuroticism (Model 7; $p=0.067$ ). By contrast, partner PA reactivity was unrelated to relationship quality (Model 5-8; all ps > 0.105). Additionally, there was no evidence for any twoway interactions of actor and partner PA reactivity with gender (Model 8; all $p \mathrm{~s}>0.105){ }^{1}$ Finally, when NA and PA actor-partner variables were included in the same model, the main effect of partner NA reactivity (Model 9; $b=-0.21, p=0.043,95 \%$ CI $[-0.41,-0.01]$ ) held.

\section{Supplemental Analyses}

In a series of supplementary analyses, we examined whether actor and partner effects of NA and PA reactivity were associated with specific dimensions of relationship quality. The results from these models can be found in Supplemental Tables S1-S6. In unadjusted models, actor NA reactivity to daily discrimination was associated with lower levels of relationship commitment (Table S1: Model 1; $b=-0.30, p=0.001,95 \%$ CI $[-0.47,-0.12])$, love (Table S3:

\footnotetext{
${ }^{1}$ Descriptive and exploratory analyses examining the role of marital status are reported in Supplemental Tables S7 and S8. There was no evidence that the association between affectivity reactivity and relationship quality varied as a function of marital status.
} 
Model 1; $b=-0.19, p=0.036,95 \%$ CI $[-0.37,-0.01])$, satisfaction (Table S5: Model 1; $b=-0.28, p=0.046,95 \%$ CI $[-0.55,-0.01])$, and trust (Table S6: Model $1 ; b=-0.30$, $p=0.032,95 \%$ CI $[-0.58,-0.03])$. However, these associations became nonsignificant in fullyadjusted models. Independent of actor effects, partner NA reactivity was associated with lower relationship commitment (Table S1: Model 1, $b=-0.21, p=0.02,95 \%$ CI $[-0.39,-0.32]$ ), passion (Table S4: Model 1, $b=-0.32, p=0.04,95 \%$ CI $[-0.62,-0.02]$ ) and satisfaction (Table S5: Model 1, $b=-0.28, p=0.05,95 \%$ CI $[-0.55,-0.00])$ in unadjusted models. However, in fully-adjusted models, only the association between partner NA reactivity and passion persisted (Table S4: Model 4, $b=-0.53, p=0.003,95 \%$ CI $[-0.88,-0.18]$ ).

Actor and partner PA reactivity also emerged as unique predictors of specific relationship dimensions in unadjusted models, with main effects of actor PA reactivity on intimacy (Table S2: Model 5, $b=-0.20, p=0.001,95 \%$ CI $[-0.31,-0.09]$ ), passion (Table S4: Model 5, $b=-0.22, p=0.004,95 \%$ CI $[-0.37,-0.07]$ ), satisfaction (Table S5: Model 5; $b=-0.24$, $p=0.001,95 \%$ CI $[-0.38,-0.11]$, trust (Table S6: Model 5; $b=-0.17, p=0.013,95 \%$ CI $[-0.31,-0.37]$ ), and partner PA reactivity on passion (Table S4: Model $5, b=-0.18, p=0.02$, 95\% CI $[-0.33,-0.04])$, respectively. However, in fully-adjusted models, only the association between partner PA reactivity and passion persisted (Table S4: Model 7, $b=-0.18, p=0.03$, 95\% CI $[-0.34,-0.02])$. Finally, when NA and PA actor-partner variables were included in the same model, only main effects for partner NA reactivity on passion (Table S4: Model 9; $b=-0.49, p=0.01,95 \%$ CI $[-0.86,-0.13])$ held.

\section{Discussion}

Racial discrimination is a salient source of chronic stress for African Americans (Clark et al., 1999), with documented adverse effects on mental and physical health (Mays et al., 2007; 
Paradies et al., 2015). Few studies have addressed the associations between racial discrimination and relationship quality in African American couples (Lavner et al., 2018; Smith et al., 2020). Accordingly, scholars have highlighted the need for research examining how the experience of day-to-day racial discrimination can have negative effects on African American couples’ relationship functioning (Bryant et al., 2010; Clark et al., 2002). Extending prior work on affective reactivity, which focused primarily on intrapersonal effects of daily stress (e.g., Charles et al., 2013; Cohen et al., 2005), this study is the first to examine links between affective reactivity to daily racial discrimination and relationship quality and the first to address these associations using dyadic data from African American couples. Results from APIM analyses add weight to the importance of considering couple processes as mechanisms linking daily stress processes to individual health. While significant associations between affective reactivity and mental health have been previously documented among African American adults (e.g., Ong \& Burrow, 2018), the present study further elucidates the interpersonal effects of racial discrimination among African American couples.

Findings indicated that participants' relationship quality was inversely associated with their partner's NA reactivity to daily racial discrimination. In supplemental analyses of specific relationship quality components, partner NA reactivity was associated with lower levels of relationship passion. This effect held in fully-adjusted models that controlled for mean levels of PA and NA and neuroticism, suggesting that the association of partner NA reactivity and relationship passion may not simply be due to mean levels of affective well-being or negative emotionality traits. While the impact of stressor spillover on intimate relationships has been widely reported (Buck \& Neff, 2012; Neff \& Karney, 2007), to our knowledge, no empirical research has addressed parallel issues in the context of African American couples' reactivity to 
daily racial discrimination and examined how differences in reactivity are linked to specific components of relationship quality. The current data are among the first to report unique links between partner NA reactivity and passion, a facet of relationship quality that is strongly associated with sexual intimacy (Baumeister \& Bratslavsky, 1999). These findings suggest more attention should be paid to the effects of racism-related stress among African American couples (Lavner et al., 2018) and that couples' everyday stress reactivity may be a particularly relevant intervention target for maintaining passion and sexual desire in intimate relationships (Neff \& Karney, 2017). Overall, the findings lend support to theoretical formulations of racial discrimination as a dyadic phenomenon (Bryant et al., 2010; Clark et al., 2002; Harrell, 2000) and suggest the need for more research that considers the negative spillover and crossover effects of daily stress on African American couple's relationship functioning (Barton et al., 2018; Neff \& Karney, 2007).

Building on previous research (Ong \& Burrow, 2018), we also considered the role of PA reactivity. While there was evidence of an association between actor PA reactivity and relationship quality, suggesting heightened vulnerability, this association was not maintained in fully-adjusted models. This is consistent with other studies suggesting the links between relationship responsiveness and health are driven by NA rather than PA reactivity (Slatcher et al., 2015; Stanton et al., 2019). Given the relative dearth of daily process studies with African American couples, research examining both actor and partner effects represents a key area for future investigation.

A key strength of the current study was the use of dyadic daily data from African American couples. At the same time, however, the study had several limitations. All measures were based on self-report data, raising concerns about common method and memory bias. Future 
investigations comparing results from daily-diary and momentary-sampling studies that incorporate physiological responses and behavior measures are thus needed. Conclusions regarding the causal direction cannot be determined given the cross-sectional analysis of relationship quality. Therefore, prospective, longitudinal studies with multiple-wave assessments of daily racial discrimination and affect and relationship quality are needed to understand the directionality and time-course of these relations. Furthermore, assessing dynamic daily stress processes (affective reactivity) as stable individual differences requires measures that are reliable and sensitive to within-person change (Ong \& Leger, 2021). A challenge in assessing the reliability of person-specific estimates (random slopes) reflecting daily affective reactivity is that it is unknown how many measurement occasions are needed for the individual slope estimates to be accurate and valid measures of interindividual differences. Future research, applying a dynamic structural equation modeling approach to larger longitudinal dyadic samples (Asparouhov et al., 2018; Olsen \& Kenny, 2006), is warranted. Finally, the current study only considered affective reactivity. Whereas reactivity reflects the magnitude of responses to stress, recovery reflects the speed with which stress responses return to baseline (Epel et al., 2018). Further daily process studies building on this work are necessary to confirm the extent to which individual differences in delayed affective recovery from daily discrimination uniquely influences interpersonal functioning, independent of exposure and affective reactivity to daily discrimination. Future research may also want to extend the findings here to explore the role of negative health behaviors (such as drinking) as a potential mechanism linking partner effects of discrimination to relationship quality (DeHart et al., 2014; Hamilton \& DeHart, 2020).

These limitations notwithstanding, results from this study demonstrate the unique role that partners play in promoting relationship quality among African American couples. The 
findings suggest that negative affective reactivity to daily racial discrimination has not only intrapersonal (Ong \& Burrow, 2018) but also interpersonal associations with health. Assessment and identification of affective reactivity as a potential vulnerability characteristic is of practical significance in suggesting factors that are malleable and can be addressed clinically (e.g., through interventions designed to teach couples how to regulate their daily negative affect in the face of daily stressors) (Neff \& Karney, 2017), For African Americans, heightened affective reactivity to daily encounters of racial discrimination may reflect an embedded history of stressor exposure. Further research that integrates personal histories of major and day-to-day experiences of discrimination is needed to better understand how racial discrimination impinges on relationship functioning. How African American couples respond to and are affected by each other's experiences of everyday racial discrimination thus remains a critical direction for future research. 
Table 1

Correlations among Primary Study Variables

\begin{tabular}{lcccccccc}
\hline \multicolumn{1}{c}{ Variable } & 1 & 2 & 3 & 4 & 5 & 6 & $M$ & $S D$ \\
\hline 1. Actor NASLP & - & $0.54^{* *}$ & $0.40^{* *}$ & 0.17 & $-0.25^{*}$ & 0.19 & 0.42 & 1.02 \\
2.Partner NASLP & $0.54^{* *}$ & - & $0.23^{*}$ & $0.32^{* *}$ & $-0.30^{* *}$ & 0.06 & 0.46 & 0.88 \\
3.Actor PASLP & $0.32^{* *}$ & 0.17 & - & $0.43^{* *}$ & $-0.31^{* *}$ & $0.36^{* *}$ & -0.001 & 1.84 \\
4.Partner PASLP & $0.23^{*}$ & $0.40^{* *}$ & $0.43^{* *}$ & - & -0.11 & 0.04 & -0.001 & 1.79 \\
5.Relationship Quality & $-0.24^{*}$ & $-0.20^{*}$ & $-0.25^{*}$ & $-0.30^{* *}$ & - & $-0.16^{*}$ & 7.70 & 1.25 \\
6.Discrimination Frequency & 0.14 & -0.01 & 0.13 & 0.08 & 0.04 & - & 4.01 & 3.43 \\
$M$ & 0.46 & 0.42 & -0.001 & -0.001 & 7.86 & 3.44 & & \\
SD & 0.88 & 1.02 & 1.79 & 1.84 & 1.13 & 3.04 & & \\
\hline
\end{tabular}

Note. Males are in the lower diagonal; females are in the upper diagonal. ${ }^{*} \mathrm{p}<.05 . * * \mathrm{p}<.01$. 
Table 2

$N A$ and $P A$ reactivity predicting relationship quality

\begin{tabular}{|c|c|c|c|c|c|c|c|c|c|}
\hline & \multicolumn{4}{|l|}{ NA } & \multicolumn{4}{|l|}{ PA } & \multirow{2}{*}{$\begin{array}{l}\text { NA and PA } \\
\text { Model } 9\end{array}$} \\
\hline & Model 1 & Model 2 & Model 3 & Model 4 & Model 5 & Model 6 & Model 7 & Model 8 & \\
\hline \multirow{2}{*}{ Actor NASLP } & $-0.201 *$ & -0.185 & 0.099 & 0.083 & & & & & 0.292 \\
\hline & 0.089 & 0.233 & 0.317 & 0.322 & & & & & 0.338 \\
\hline \multirow[t]{2}{*}{ Partner NA $\mathrm{SLP}_{\mathrm{S}}$} & $-0.195 *$ & $-0.190 *$ & $-0.209 *$ & $-0.215 *$ & & & & & $-0.212 *$ \\
\hline & 0.088 & 0.089 & 0.097 & 0.098 & & & & & 0.103 \\
\hline \multirow[t]{2}{*}{ Actor NASLP $*$ Gender } & & & & 0.049 & & & & & 0.066 \\
\hline & & & & 0.115 & & & & & 0.112 \\
\hline \multirow[t]{2}{*}{ Partner NA $\mathrm{SLP}^{*}$ Gender } & & & & -0.069 & & & & & -0.160 \\
\hline & & & & 0.114 & & & & & 0.118 \\
\hline \multirow[t]{2}{*}{ Actor PA $\mathrm{SLP}_{\mathrm{SL}}$} & & & & & $-0.152 * *$ & $-0.475 *$ & -0.458 & -0.420 & -0.481 \\
\hline & & & & & 0.044 & 0.216 & 0.067 & 0.245 & 0.268 \\
\hline \multirow[t]{2}{*}{ Partner PASLP } & & & & & -0.073 & -0.063 & -0.055 & -0.048 & -0.023 \\
\hline & & & & & 0.045 & 0.045 & 0.047 & 0.047 & 0.050 \\
\hline \multirow[t]{2}{*}{ Actor PA $A_{S L P} *$ Gender } & & & & & & & & 0.007 & 0.010 \\
\hline & & & & & & & & 0.055 & 0.056 \\
\hline \multirow{2}{*}{ Partner PASLP*Gender } & & & & & & & & 0.088 & 0.100 \\
\hline & & & & & & & & 0.054 & 0.055 \\
\hline NA on non-racial & & -0.024 & -0.172 & -0.166 & & & & & -0.296 \\
\hline discrimination days & & 0.183 & 0.245 & 0.248 & & & & & 0.256 \\
\hline Racial discrimination & & 0.016 & 0.025 & 0.025 & & 0.031 & 0.041 & 0.036 & 0.039 \\
\hline frequency & & 0.026 & 0.027 & 0.027 & & 0.025 & 0.026 & 0.027 & 0.028 \\
\hline PA on non-racial & & & & & & -0.288 & -0.311 & -0.280 & -0.333 \\
\hline discrimination days & & & & & & 0.197 & 0.225 & 0.222 & 0.241 \\
\hline \multirow[t]{2}{*}{ Neuroticism } & & & -0.091 & -0.086 & & & -0.065 & -0.069 & -0.055 \\
\hline & & & 0.064 & 0.064 & & & 0.062 & 0.062 & 0.065 \\
\hline \multirow[t]{2}{*}{ Age } & & & 0.002 & -0.000 & & & 0.003 & 0.004 & -0.004 \\
\hline & & & 0.009 & 0.009 & & & 0.010 & 0.010 & 0.010 \\
\hline \multirow[t]{2}{*}{ Gender ( $1=$ female $)$} & & & 0.017 & 0.025 & & & -0.075 & -0.074 & 0.015 \\
\hline & & & 0.082 & 0.092 & & & 0.075 & 0.073 & 0.091 \\
\hline \multirow[t]{2}{*}{ Income } & & & -0.190 & -0.198 & & & -0.197 & -0.194 & -0.185 \\
\hline & & & 0.100 & 0.102 & & & 0.103 & 0.103 & 0.103 \\
\hline \multirow{2}{*}{$\begin{array}{l}\text { Marriage status } \\
(1=\text { married })\end{array}$} & & & -0.023 & -0.049 & & & -0.023 & 0.003 & -0.108 \\
\hline & & & 0.227 & 0.233 & & & 0.232 & 0.230 & 0.233 \\
\hline \multirow[t]{2}{*}{ Relationship length } & & & -0.009 & -0.007 & & & -0.011 & -0.014 & -0.007 \\
\hline & & & 0.016 & 0.016 & & & 0.016 & 0.016 & 0.016 \\
\hline
\end{tabular}

Note. Standard errors below unstandardized coefficient values, NA= Negative Affect; PA= Positive Affect; SLP= Slope. Bolded items are those that are significant at the ${ }^{*} p<.05, * * p<.01, \dagger p=.05$ levels. 
Author Contributions: A. Ong and B. Urganci. developed the study concept. T. DeHart and A. Burrow contributed to the study design and data collection. B. Urganci performed the data analysis and interpretation under the supervision of A. Ong. A. Ong drafted the manuscript, and T. DeHart, A. Burrow, and B. Urganci provided critical revisions. All authors approved the final version of the manuscript for submission.

Funding: This research was supported, in part, by Award \#1151323 from the Division of Behavioral and Cognitive Science at the National Science Foundation (NSF) awarded to the third and fourth authors.

Acknowledgements: We are extremely grateful to Natalie Hallinger and Hannah Hamilton who supervised the many undergraduate research assistants who helped with data collection. We thank all of the couples who took time out of their daily lives to participate in this research. 


\section{References}

Aron, A., et al. (1991). Close relationships as including other in the self. Journal of Personality and Social Psychology, 60, 241-253.

Arriaga, X. B. (2013). An interdependence theory analysis of close relationships. In J. A. Simpson \& L. Campbell (Eds.), The Oxford handbook of close relationships (pp. 39-65). Oxford University Press.

Asparouhov, T., et al. (2018). Dynamic structural equation models. Structural Equation Modeling, 25, 359-388.

Barnes, L. L., et al. (2004). Racial differences in perceived discrimination in a community population of older blacks and whites. Journal of Aging and Health, 16, 315-337.

Barton, A. W., et al. (2018). Stress spillover, African Americans' couple and health outcomes, and the stress-buffering effect of family-centered prevention. Journal of Family Psychology, 32, 186-196.

Baumeister, R. F., \& Bratslavsky, E. (1999). Passion, intimacy, and time: Passionate love as a function of change in intimacy. Personality and Social Psychology Review, 3, 49-67.

Bolger, N., et al. (1989). Effects of daily stress on negative mood. Journal of Personality and Social Psychology, 57(5), 808-818.

Bolger, N., et al. (1990). The microstructure of daily role-related stress in married couples. In S. Gore \& J. Eckenrode (Eds.), Stress between work and family. (pp. 95-115). Plenum Press.

Bolger, N., \& Schilling, E. A. (1991). Personality and the problems of everyday life: The role of neuroticism in exposure and reactivity to daily stressors. Journal of Personality, 59(3), 355-386. 
Bolger, N., \& Zuckerman, A. (1995). A framework for studying personality in the stress process. Journal of Personality and Social Psychology, 69(5), 890-902.

Bryant, C. M., et al. (2010). Race matters, even in marriage: Identifying factors linked to marital outcomes for African Americans. Journal of Family Theory \& Review, 2, 157-174.

Bryk, A. S., \& Raudenbush, S. W. (1992). Hierarchical linear models: Applications and data analysis methods. Thousand Oaks, CA, US: Sage Publications, Inc.

Buck, A. A., \& Neff, L. A. (2012). Stress spillover in early marriage: The role of self-regulatory depletion. Journal of Family Psychology, 26, 698-708.

Charles, S. T., et al. (2013). The wear-and-tear of daily stressors on mental health. Psychological Science, 24, 733-741.

Chatters, L. M., et al. (2008). Religious participation and DSM-IV disorders among older African Americans: Findings from the National Survey of American Life (NSAL). American Journal of Geriatric Psychiatry, 16, 957-965.

Chiang, J. J., et al. (2018). Affective reactivity to daily stress predicts 20-year mortaligy risk in adults with chronic illness: Findings from the national study of daily experience. Health Psychology, 37, 170-178.

Clark, R., et al. (2002). Racism as a stressor for Blacks: A biopsychosocial model. In T. A. LaVeist (Ed.), Race, ethnicity, and health: A public health reader (pp. 319 - 339). Jossey-Bass.

Clark, R., et al. (1999). Racism as a stressor for African Americans: A biopsychosocial model. American Psychologist, 54(10), 805-816.

Cohen, J. H., et al. (2005). Daily affective reactivity as a prospective predictor of depressive symptoms. Journal of Personality, 73, 1687-1713. 
Cuevas, A., et al. (2020). Discrimination and systemic inflammation: A critical review and synthesis. Brain, Behavior, and Immunity, 89, 465-479.

DeHart, T., et al. (2014). A diary study of perceived mistreatment and alcohol consumption in college students. Basic and Applied Social Psychology, 36, 443-451.

Doyle, D. M., \& Molix, L. (2014). How does stigma spoil relationships? Evidence that perceived discrimination harms romantic relationship quality through impaired self-image. Journal of Applied Social Psychology.

Eckenrode, J., \& Bolger, N. (1997). Daily and within-day event measurement. In R. C. Kessler \& S. Cohen (Eds.), Measuring stress: A guide for health and social scientists (pp. 80-101). Oxford University Press.

Epel, E. S., et al. (2018). More than a feeling: A unified view of stress measurement for population science. Frontiers in Neuroendocrinology, 49, 146-169.

Fletcher, G. J., et al. (2000). The measurement of perceived relationship quality components: A confirmatory factor analytic approach. Personality and Social Psychology Bulletin, 26, 340-354.

Forman, T. A., et al. (1997). Race, place, and discrimination. Perspectives on Social Problems, 9, 231-261.

Garcia, R. L., \& Kenny, D. A. (2020). dyadr: Dyadic Data Analysis. In (Version 0.0.0.9000) https://rdrr.io/github/RandiLGarcia/dyadr/

Goldberg, L. R. (1992). The development of markers for the Big-Five factor structure. Psychological Assessment, 4, 26-42.

Goosby, B. J., et al. (2018). Stress-related biosocial mechanisms of discrimination and African American health inequities. Annual Review of Sociology, 44, 319-340. 
Gunthert, K. C., et al. (1999). The role of neuroticism in daily stress and coping. Journal of Personality and Social Psychology, 77(5), 1087-1100.

Hamilton, H. R., \& DeHart, T. (2020). Cheers to equality! Both hostile and benevolent sexism predict increases in college women's alcohol consumption. Sex Roles, 83, 675-684.

Harrell, S. P. (1997). The Racism and Life Experiences Scales (RaLES). Unpublished manuscript.

Harrell, S. P. (2000). A multidimensional conceptualization of racism-related stress: Implications for the well-being of people of color. American Journal of Orthopsychiatry, 70(1), 42-57.

Karney, B. R., \& Bradbury, T. N. (1995). The longitudinal course of marital quality and stability: A review of theory, methods, and research. psychological Bulletin, 118, 3-34.

Kashy, D. A., \& Kenny, D. A. (2000). The analysis of data from dyads and groups. In (2000). Judd, Charles $M(E d)$, Reis, Harry $T(E d)$, Handbook of research methods in social and personality psychology. (pp.451 477). New York, NY, US: Cambridge University Press. xii, $558 \mathrm{pp}$.

Kerr, J., et al. (2018). The impact of racial discrimination on African American fathers' intimate relationships. Race and Social Problems, 10, 134-144.

Kessler, R. C., \& McLeod, J. D. (1984). Sex differences in vulnerability to undesirable life events. American Sociological Review, 49(5), 620-631.

Kessler, R. C., et al. (1999). The prevalence, distribution, and mental health correlates of percieved discrimination in the United States. Journal of Health and Social Behavior, 40(3), 208-230.

Lavner, J. A., et al. (2018). Racial discrimination and relationship functioning among African American couples. Journal of Family Psychology, 32, 686-691. 
Lee, D. B., et al. (2020). The Daily Life Experiences Scale. Factor structure, reliability, validity, and measurement invariance for African American males and females. Measurement and Evaluation in Counseling and Development, 1-14.

Lewis, T. T., et al. (2015). Self-reported experiences of discrimination and health: Scientific advances, ongoing controversies, and emerging issues. Annual Review of Clinical Psychology, 11, 407-440.

Lewis, T. T., et al. (2012). Racial/ethnic differences in responses to the Everyday Discrimination Scale: A differential item functioning analysis. American Journal of Epidemiology, 175, $391-401$.

Lilienfeld, S. O. (2017). Microaggressions: Strong claims, inadequate evidence. Perspectives on Psychological Science, 12, 138-169. https://doi.org/10.1177/1745691616659391

Lincoln, K. D., \& Chae, D. H. (2010). Stress, marital satisfaction, and psychological distress among African Americans. Journal of Family Issues, 31, 1081-1105.

Mays, V. M., et al. (2007). Race, race-based discrimination, and health outcomes among African Americans. Annual Review of Psychology, 58, 201-225.

McNeil, S. N., et al. (2014). Does spousal support moderate the association between perceived racial discrimination and depressive symptoms among African American couples? Family Process, 53(1), 109-119.

Merritt, M. M., et al. (2011). How much striving is too much? John Henryism active coping predicts worse daily cortisol responses for African-American but not White female dementia family caregivers. American Journal of Geriatric Psychiatry, 19, 451-460. 
Mroczek, D. M., et al. (2012). Emotional reactivity predicts mortality: Longitudinal findings from the VA Normative Aging Study. Journal of Gerontology: Psychological Sciences, 70(3), 396-406. https://doi.org/10.1093/geronb/gbt107

Murry, V. M., et al. (2001). Racial discrimination as a moderator of the links among stress, maternal psychological functioning, and family relationships. Journal of Marriage and Family, 63, 915-926.

Neff, L. A., \& Karney, B. R. (2007). Stress crossover in newlywed marriage: A longitudinal and dyadic perspective. Journal of Marriage and Family, 69, 594-607.

Neff, L. A., \& Karney, B. R. (2017). Acknowledging the elephant in the room: how stressful environmental contexts shape relationship dynamics. Current Opiniion in Psychology, $13,107-110$.

O’Neill, S., et al. (2004). Affective reactivity to daily interpersonal stressors as a prospective predictor of depressive symptoms. Journal of Social and Clinical Psychology, 23, 172194.

Olsen, J. A., \& Kenny, D. A. (2006). Structural equation modeling with interchangeable dyads. Psychological Methods, 11, 127-141.

Ong, A. D. (2021). Racial incivility in everyday life: A conceptual framework for linking process, person, and context. Perspectives on Psychological Science.

Ong, A. D., \& Burrow, A. L. (2018). Affective reactivity to daily racial discrimination as a prospective predictor of depressive symptoms in African American graduate and postgraduate students. Development and Psychopathology, 30, 1649-1659.

Ong, A. D., et al. (2013). Linking stable and dynamic features of positive affect to sleep. Annals of Behavioral Medicine, 46, 52-61. 
Ong, A. D., et al. (2009). Racial discrimination and the stress process. Journal of Personality and Social Psychology, 96(6), 1259-1271.

Ong, A. D., et al. (2020). Affective reactivity, resting heart rate variability, and marital quality: A 10-year longitudinal study of U.S. adults. Journal of Family Psychology, 34, 375-882.

Ong, A. D., \& Leger, K. A. (2021). Advancing the study of resilience to daily stressors. Perspectives on Psychological Science.

Paradies, Y., et al. (2015). Racism as a determinant of health: a systematic review and metaanalysis. PLOS ONE.

Parrish, B., et al. (2011). Prospective relationship between negative affective reactivity to daily stress and depressive symptoms. Journal of Social and Clinical Psychology, 30, 270-296.

Piazza, J. R., et al. (2013). Affective reactivity to daily stressors and long-term risk of reporting a chronic physical health condition. Annals of Behavioral Medicine, 45, 110-120.

Piazza, J. R., et al. (2019). Age, daily stress processes, and allostatic load: A longitudinal study. Journal of Aging and Health, 31, 1671-1691.

Pieterse, A. L., et al. (2012). Perceived racism and mental health among Black American adults: A meta-analytic review. Journal of Counseling Psychology, 59, 1-9.

Priest, J. B., et al. (2020). Discrimination, family emotional climate, and African American health: An application of the BBFM. Journal of Family Psychology, 34, 598-609.

Raudenbush, S. W., \& Bryk, A. S. (2002). Hierarchical linear models: Applications and data analysis methods (2nd ed.). Sage.

Rusbult, C. E., \& Van Lange, P. A. M. (1996). Interdependence processes. In E. T. Higgins \& A. W. Kruglanski (Eds.), Social psychology: Handbook of basic principles (pp. 564-596). The Guilford Press. 
Sin, N. L., et al. (2015). Positive and negative affective responses to daily stressors are associated with inflammation. Health Psychology, 34, 1154-1165.

Slatcher, R. B., \& Selcuk, E. (2017). A social psychological perspective on the links between close relationships and health. Current Directions in Psychological Science, 26, 16-21.

Slatcher, R. B., et al. (2015). Partner responsiveness predicts diurnal cortisol profiles 10 years later. Psychological Science., 26, 972-982.

Smith, S. M., et al. (2020). Racial discrimination, racism-specific support, and self-reported health among African American couples. Journal of Social and Personal Relationships, 37, 779-799.

St. Jean, Y., \& Feagin, J. R. (1998). The family costs of white racism: the case of African American families. Journal of Comparative Family Studies, , 29, 297-312.

Stanton, S. C., et al. (2019). Perceived partner responsiveness, daily negative affect reactivity, and all-cause mortality: A 20-year longitudinal study. Psychosomatic Medicine, 81, 7-15.

Thompson, A., \& Bolger, N. (1999). Emotional transmission in couples under stress. Journal of Marriage and the Family, 61(1), 38-48.

Trail, T. E., et al. (2012). The costs of racism for marriage: How racial discrimination hurts, and ethnic identity protects, newlywed marriages among Latinos. Personality and Social Psychology Bulletin, 38, 454-465.

Utsey, S. O. (1998). Assessing the stressful effects of racism: A review of instrumentation. Journal of Black Psychology, 24(3), 269-288.

Watson, D., et al. (1988). Development and validation of brief measures of positive and negative affect: The PANAS scales. Journal of Personality and Social Psychology, 54(6), 10631070. 
Williams, D. R., et al. (2019). Understanding how discrimination can affect health. Health Services Research, 54, 1374-1388.

Williams, D. R., et al. (2003). Racial/ethnic discrimination and health: Findings from community studies. American Journal of Public Health, 93(2), 200-208.

Wofford, N., et al. (2019). The vicarious effects of discrimination: How partner experiences of discrimination affect individual health. Social Psychological and Personality Science, 10, 121-130. 